\title{
Differential upregulation of the hypothetical transmembrane protein 66 (TMEM66) in multiple sclerosis patients with potential inflammatory response
}

\author{
SAFA TAHA $^{1}$, MUNA ALJISHI $^{1}$, ISA ALSHAROQI ${ }^{2}$ and MOIZ BAKHIET ${ }^{1}$ \\ ${ }^{1}$ Department of Molecular Medicine, Princess Al-Jawhara Center for Genetics and Inherited Diseases, \\ College of Medicine and Medical Sciences, Arabian Gulf University; \\ ${ }^{2}$ Department of Clinical Neurosciences, Salmaniya Medical Complex, Manama, Bahrain
}

Received September 25, 2014; Accepted October 15, 2014

DOI: 10.3892/br.2014.390

\begin{abstract}
The prevalence of multiple sclerosis (MS) in the Gulf region has markedly increased during the last decade, but the mechanisms of the disease have not been investigated. The present study aimed to understand the molecular processes involved in the disease development of the recently emerged MS in this population using microarray technology to investigate differentially-expressed novel genes in MS patients compared to healthy-matched subjects. The expression of the upregulated genes was confirmed by quantitative polymerase chain reaction (qPCR). Furthermore, gene cloning, protein expression and purification were performed followed by testing of the obtained recombinant protein on biological assays, including cell proliferation and cytokine mRNA detection by reverse transcriptase-qPCR. The results showed that out of $\sim 50,000$ genes, the hypothetical transmembrane protein- 66 gene (TMEM66) exhibited a 3 times higher expression in MS patients compared to healthy subjects. The TMEM66 gene was cloned and its protein showed marked immunological activity relevant to MS since significant proliferation $(\mathrm{P}<0.05)$ and augmented induction of the proinflammatory cytokines, interleukin (IL)- 6 , interferon- $\gamma$, tumor necrosis factor- $\alpha$, and the chemokines, chemokine ligand 5/chemokine receptor 5, macrophage inflammatory protein $1 \alpha$ (MIP- $1 \alpha)$ and MIP- $1 \beta$ were recorded, but not the anti-inflammatory cytokines, IL-4 or IL-2. In conclusion, TMEM66 may be associated with the molecular events of MS and may be considered as an MS biomarker for future personalized medicine management approaches.
\end{abstract}

Correspondence to: Professor Moiz Bakhiet, Princess Al-Jawhara Center for Genetics and Inherited Diseases, College of Medicine and Medical Sciences, Arabian Gulf University, P.O. Box 26671, Manama, Bahrain

E-mail: moiz@agu.edu.bh

Key words: cytokine, chemokine, proliferation, gene expression, microarray

\section{Introduction}

Multiple sclerosis (MS) is an immune-mediated inflammatory demyelinating disease of the central nervous system, which is frequently initiated in early adult life and continues a variable course that may progress in numerous patients, eventually resulting in significant morbidity. Various genetic, immunological and environmental factors have been associated with inducing the onset and progression of the disease (1-3). Genetics may play a role in the disease pathogenesis as MS is more common in the Caucasian population and the frequency of MS appears to increase with the distance from the Equator in the two hemispheres (4). MS mainly affects young adults and is more prevalent in females. The frequency in the USA and Northern Europe is 100 per 100,000 people (5). There is a universal increase in the prevalence and incidence of MS over time. In the Middle East, and particularly the Gulf region, an increased prevalence has been recently reported (6-8) due to genetic and environmental factors, particularly following the most recent wars in the region (9), with a similar increase in Bahrain (Alsharoqi et al, 2014, unpublished data).

Pathologically, MS is identified by perivascular infiltration of monocytes and lymphocytes, mainly cluster of differentiation 4 (CD4) cells, within the brain and spinal cord that cause myelin destruction (10). Peripheral blood mononuclear cells (PBMCs) are involved in MS pathogenesis and induce active nerve demyelination. Autoreactive activated T-cells invade the blood brain barrier and initiate an inflammatory response that results in myelin destruction and significant neurological disability (11). Adhesion molecules, chemokines, cytokines, T-cell and macrophage infiltration are the main immune mediators that are involved in active MS lesions. Additionally, it is considered that the proinflammatory and anti-inflammatory responses have clear effects over the time of MS progression (12).

To improve the understanding of MS pathogenesis in a certain population and to mark novel treatment approaches to identify patients with poor prognosis, new broad approaches are required, such as gene expression. Microarray technology is efficient at comprehensive detection and quantification of large numbers of gene transcripts simultaneously (13). It provides 
detailed insight into cellular mechanisms that are involved in gene expression regulation and permits novel understanding of signaling networks that function within cells or tissues and of the molecular processes involved (14). Microarray was used to evaluate the overall gene expression patterns and to understand the composition of the genetic regulatory networks and the mechanisms involved in MS $(11,15)$.

In order to examine such gene expression in Bahraini MS patients, that may be associated with the pathogenesis of the disease in response to the emerged environmental factors (9) and via epigenetic mechanisms (2) for the initiation of molecular-targeted approaches to personalized therapy, microarray technology was utilized in the present study to analyze differential gene upregulation in PBMCs isolated from Bahraini MS patients in comparison to healthy subjects. The differential novel gene expression was shown in the Bahraini MS patients, the gene was cloned and protein showed potential immunological activity.

\section{Materials and methods}

Subjects. The study was approved by the Ethics Committee of the Arabian Gulf University, Manama, Bahrain, and included 25 randomly-selected Bahraini MS patients who were newly diagnosed at the Salmaniya Medical Complex (Manama, Bahrain) as relapse remission MS (male and female, 20-40 years) and were not treated with disease-modifying drugs. The patients were all Arab with the same ethnic background. All the MS patients recruited for the study were assessed independently by a neurologist and were diagnosed clinically and radiologically according to the Modified McDonald criteria 2010 (Dublin 2010) (16). A similar number of healthy Bahraini individuals were used as controls with matched age and gender, and without nervous system pathology. All the participants had peripheral blood counts within the reference range. All the subjects were required to sign an informed consent form prior to entering the study.

RNA isolation and microarray expression profiling using microarray. PBMCs were separated on a Ficol-Histopaque-1077 (Sigma, St. Louis, MO, USA) by density-gradient centrifugation. The cells were lysed and total RNA was purified by TRIzol reagent (Ambion, Austin, TX, USA). The quantity and purity of RNA samples were confirmed by spectrophotometer and agarose gel electrophoresis. Microarray experiments were carried out as described previously (17). Briefly, the GeneChip ${ }^{\circledR}$ 3' IVT Express kit (Affymetrix, Santa Clara, CA, USA) was used for target RNA preparation for microarray expression analysis. In total, $100 \mathrm{ng}$ input RNA was used to first synthesize the cDNA strand. This cDNA was subsequently converted into a double-stranded DNA, in vitro transcripted to synthesize amplified RNA (aRNA), which incorporated a biotin-conjugated nucleotide (aRNA), and was purified, fragmented, labeled and hybridized to a GeneChip array (HG-U133_Plus_2; Affymetrix). Gene chips were scanned using the GeneChip Scanner $30007 \mathrm{G}$ and Command Console Software (AGCC) version 1.0 according to the manufacturer's instructions (Affymetrix).

cDNA synthesis and Roche quantitative polymerase chain reaction $(q P C R)$. cDNA samples were synthesized using an anchored oligo(dT)18 primer (Transcriptor First Strand cDNA synthesis kit; Roche Diagnostics, Milan, Italy). For the LightCycler reaction, a dual color assay was performed using a Roche Universal Probe Library (UPL) probe specific for the hypothetical transmembrane protein-66 gene (TMEM66) and a reference gene, the hypoxanthine phosphorybosyl transferase (HPRT) probe, was used as the internal control. TMEM66 UPL probe was labeled with FAM, whereas the $H P R T$ reference probe was labeled with Yellow 555. A relative standard curve was created using a serial dilution of positive sample $(1,400,700,350,175$ and $87.5 \mathrm{ng})$, in which the concentration is expressed in relative units $(1,0.5,0.25,0.125$ and 0.0625). A Master mix of the following reaction components was prepared to the indicated end-concentration: $9 \mu 1$ water, $0.4 \mu 1$ TMEM66 forward primer $(0.4 \mu \mathrm{M}), 0.4 \mu 1$ TMEM66 reverse primer $(0.4 \mu \mathrm{M}), 0.4 \mu \mathrm{l}$ TMEM66 UPL probe $(0.2 \mu \mathrm{M})$, $0.4 \mu \mathrm{l} H P R T$ forward and reverse primer mix $(0.4 \mu \mathrm{M}), 0.4 \mu \mathrm{l}$ HPRT UPL probe $(0.2 \mu \mathrm{M})$ and $4.0 \mu \mathrm{l}$ of LightCycler TaqMan DNA Master (Roche Diagnostics). A total of $15 \mu \mathrm{l}$ LightCycler Master mix was added to $5 \mu \mathrm{l}$ cDNA samples of the control and MS samples, where it was used as a PCR template into the LightCycler capillaries. The following LightCycler experimental run protocol was used: Denaturation program at $95^{\circ} \mathrm{C}$ for $10 \mathrm{~min}$, amplification and quantification program repeated 45 times at $95^{\circ} \mathrm{C}$ for $10 \mathrm{sec}, 60^{\circ} \mathrm{C}$ for $30 \mathrm{sec}$ and $72^{\circ} \mathrm{C}$ for $1 \mathrm{sec}$ with a dual fluorescence measurement at 530 and $560 \mathrm{~nm}$ and finally a cooling step at $40^{\circ} \mathrm{C}$ for $30 \mathrm{sec}$. For the mathematical model, it is necessary to determine the crossing points (CP) for each transcript. CP is defined as the point at which the fluorescence rises significantly above the background fluorescence. 'Fit point method' must be performed in the LightCycler software 4.1 (Roche Diagnostics), at which CP will be measured at constant fluorescence level (18).

TMEM66 gene cloning, protein expression and purification. To express the TMEM66 protein, the plasmid pT7CFE1-CHis vector (Thermo Scientific, Rockford, IL, USA) was constructed with the cDNA clone (GenBank: DQ895663), which expresses the full-length TMEM66 protein in the NdeI/XhoI cloning site. The pT7CFE1-CHis vector was subsequently used to transform competent Escherichia coli (E. coli) DH5 $\alpha$. The transformed bacteria were grown on an ampecillin-Luria-Bertani (LB) agar plate and incubated at $37^{\circ} \mathrm{C}$ overnight. A single large colony was selected and grown further in $5 \mathrm{ml} \mathrm{LB}$ broth containing $5 \mu \mathrm{l}$ of $100 \mathrm{mg} / \mu \mathrm{l}$ ampecillin overnight at $37^{\circ} \mathrm{C}$ with agitation at $350 \mathrm{rpm}$. The pre-culture of $E$. coli $(5 \mathrm{ml})$ containing pT7CFE1-CHis was added to $100 \mathrm{ml}$ fresh $\mathrm{LB}$ medium and grown at $37^{\circ} \mathrm{C}$ to a cell density of $0.6-0.8$ (A650). The culture was further grown at $35^{\circ} \mathrm{C}$ for $3-4 \mathrm{~h}$ after induction with isopropyl $\beta$-D-1-thiogalactopyranoside (Sigma-Aldrich) to a final concentration of $1 \mathrm{mM}$ (19). The cells were centrifuged for $10 \mathrm{~min}$ at $15,000 \mathrm{~g}$ and the cell pellets were suspended in lysis buffer [50 mM Tris $(\mathrm{pH} \mathrm{8.0)}$, $10 \%$ glycerol, $0.1 \%$ Triton X-100, $100 \mu \mathrm{g} / \mathrm{ml}$ lysozyme, $1 \mathrm{mM}$ phenylmethanesulfonyl fluoride (PMSF), 3 units of DNase and $2 \mathrm{mM} \mathrm{MgCl} 2$. Lysosomes and PMSF (P7626; Sigma-Aldrich) were immediately added prior to the experiment. DNase was added following sonication. The pellet was incubated at $30^{\circ} \mathrm{C}$ for $15 \mathrm{~min}$, sonicated and centrifuged at $17,418 \mathrm{x} \mathrm{g}$ for $20 \mathrm{~min}$ at $4^{\circ} \mathrm{C}$. The supernatant was collected in new tubes 
and the pellets were resuspended in lysis buffer. Cell lysate was frozen at $-20^{\circ} \mathrm{C}$ subsequent to obtaining $20 \mu \mathrm{l}$ from the supernatant and pellet portions for SDS-PAGE analysis. The supernatant containing the TMEM66-His protein was purified by HisPur Cobalt Purification kit (Thermo Scientific). The presence of the purified product was confirmed by SDS-PAGE and western blot using anti-TMEM66 antibody (ab80890; Abcam, Cambridge, MA, USA). A rabbit polyclonal antibody to TMEM66 was used as the primary antibody, whereas biotinylated goat anti-rabbit as secondary antibody. The detection was performed using the colorimetric western blot kit: MaxTag TMB/DAB substrate (Rockland Immunochemicals, Inc., Gilbertsville, PA, USA) (19).

WST cell proliferation assay. Fast, sensitive quantification of cell proliferation and viability was monitored using the Quick Cell Proliferation assay kit (catalog no. BV-K301-10; BioVision, Inc., Milpitas, CA, USA). The assay is based on the cleavage of the tetrazolium salt, WST-1, to formazan by cellular mitochondrial dehydrogenases. Expansion in the number of viable cells resulted in an increase in the overall activity of the mitochondrial dehydrogenases in the sample. The augmentation in enzyme activity leads to an increase in the amount of formazan dye formed. The reagent was prepared by dissolving the lyophilized WST-1 reagent with $5 \mathrm{ml}$ of the electro coupling solution (ECS). The Cell Proliferation assay procedures were followed as the manufacturer instructed. Briefly, blood samples were collected from apparently healthy volunteers into EDTA tubes. Human peripheral blood mononuclear cells (hPBMCs) were separated by the Ficol-Hypaque gradient (Sigma), counted and cultured in triplicate in a 96-well microtiter plate in a final volume of $100 \mu \mathrm{l} /$ well culture medium [RPMI-1640 (Sigma), supplemented with $10 \%$ fetal bovine serum, $2 \%$ glutamine and $1 \%$ penicillin-streptomycin] at $1 \times 10^{5}$ cells/well. Subsequently, the cells were stimulated with TMEM66 protein at different serial concentrations (340, 170, 85, 42.5, 21.25 , 10.6, 5.3, 2.66 and $1.33 \mathrm{ng}$ ). The negative (unstimulated cells) and positive controls (stimulated cells with $5 \mu \mathrm{g} / \mathrm{ml} \mathrm{PHA}-\mathrm{M}$ ) were included. The cells were incubated at $37^{\circ} \mathrm{C}$ in a $5 \% \mathrm{CO}_{2}$ incubator for 24-72 h. Subsequently, $10 \mu \mathrm{l} /$ well of WST-1/ECS solution was added and incubated for $4 \mathrm{~h}$ in standard culture conditions. Following thorough agitation for $1 \mathrm{~min}$ on a shaker, the absorbance of the treated and untreated samples was measured using a microtiter plate reader at $450 \mathrm{~nm}$ and the reference wavelength at $>600 \mathrm{~nm}(20,21)$.

Reverse-transcription (RT)-PCR. To investigate the effect of TMEM66 protein in terms of cytokines, chemokines and adhesion molecules expression on healthy PBMCs samples, RT-PCR was performed. PBMCs were purified by the Histopaque method, washed, counted and cultured in complete growth medium at a concentration of 100,000 cells per $100 \mu \mathrm{l} /$ well. The cells were treated with 340 ng TMEM66 protein and cultured at $37^{\circ} \mathrm{C}, 5 \% \mathrm{CO}_{2}$ for $60 \mathrm{~min}$ and $24 \mathrm{~h}$. RNA was extracted from each TMEM66-treated and untreated samples at $60 \mathrm{~min}$ and after $24 \mathrm{~h}$ by TRIzol ${ }^{\circledR}$ reagent (Invitrogen Life Technologies, Carlsbad, CA, USA) (22-24).

Activity of TMEM66 protein on cytokine and chemokine gene expression. cDNA was synthesized using $1 \mu \mathrm{g}$ total RNA and the cDNA synthesis kit (Roche Diagnostics) at the following temperatures: $10 \mathrm{~min}$ at $25^{\circ} \mathrm{C}, 60 \mathrm{~min}$ at $42^{\circ} \mathrm{C}$ and $5 \mathrm{~min}$ at $99^{\circ} \mathrm{C}$.

RT-PCR reactions contained $250 \mathrm{ng}$ cDNA, 1.2 unit of Taq DNA polymerase (Eppendorf, Hamburg, Germany), $1 \mathrm{X}$ PCR buffer (Eppendorf), $0.2 \mu \mathrm{M}$ of each primer, $0.2 \mathrm{mM}$ of each dNTP and $2 \mathrm{mM} \mathrm{MgCl}_{2}$, in a final volume of $50 \mu \mathrm{l}$. The expression of different cytokines, chemokines and adhesion molecules were measured by RT-PCR technology. These included tumor necrosis factor (TNF)- $\alpha$, interferon (IFN)- $\alpha$, interleukin (IL)-2, IL-4, IL-6, macrophage inflammatory protein $1 \alpha$ (MIP-1 $\alpha$ ) MIP1- $\alpha$, MIP1- $\beta$, chemokine receptor 5 (CCR5) and chemokine ligand 5 (CCL5). Amplification and expression of the cytokines and chemokines at different intervals following induction with TMEM66 protein were determined by $2 \%$ gel electrophoresis stained with ethidium bromide and visualized by UV light.

Statistical analysis. Data analysis was performed by Partek Genomics Suite software (http://www.partek.com).

All the images of the raw CEL files were investigated visually and the expression value was computed from the raw CEL files by applying the Robust Multi-Chip Average (RMA) background correction algorithm (25), which included value background correction, quantile normalization, $\log 2$ transformation and median polish summarization. Furthermore, the basic Affymetrix quality control measurements were assessed using the Affymetrix Expression Console software (average background, scale factor, percent present and $3^{\prime}$ to $5^{\prime}$ ratio). The samples that showed deviant values in these initial quality assessments were also deviant in primitive clustering and component analysis and were therefore removed from further analysis. Summarization of probe set intensity, background correction and normalization was performed using the Partek implementation of the GeneChip RMA algorithm (26). Prior to statistical analyses, the genes whose expression levels did not vary in the sample population (inter quartile range, 0.5 ) were removed. Analysis of variance multiple model analysis was applied. The source of variation, non-relevant batches effects, such as date and working batch, were analyzed and eliminated. Fold ratio, fold change (FC) and P-value were calculated for each gene in all the samples.

In the proliferation assay, the Student's t-test was used to determine the level of significance between two groups. $\mathrm{P}<0.05$ was considered to indicate a statistically significant difference.

\section{Results}

Identification of the differentially expressed genes between $M S$ patients and healthy subjects. The extracted RNA samples were selected according to purity, integrity and quantity. A total of 100 ng RNA samples were used with a high purity and high ratio of $\lambda 260 / 280(1.8 \rightarrow 1.9)$. All the microarrays used in analysis passed all the stringent quality control criteria. The gene expression measurement that was used in the study is available and can be downloaded from Gene Expression Omnibus (http://www.ncbi.nlm.nih.gov/geo/). Quality control metrics are generated from importing the CEL files of all the samples. The quality control information from the control 
Table I. Upregulated transcripts of the multiple sclerosis patients compared to the healthy subjects.

\begin{tabular}{|c|c|c|c|}
\hline Gene symbol & Gene title & Fold change & P-value \\
\hline SMCHD1 & Structural maintenance of chromosomes flexible hinge domain containing 1 & 8.895 & 0.002 \\
\hline ANXA3 & Annexin A3 & 6.616 & 0.029 \\
\hline$R G S 1$ & Regulator of G-protein signaling 1 & 4.926 & 0.006 \\
\hline$M A F F$ & v-Maf musculoaponeurotic fibrosarcoma oncogene homolog F (avian) & 4.897 & 0.012 \\
\hline TNFAIP3 & Tumor necrosis factor, $\alpha$-induced protein 3 & 4.471 & 0.015 \\
\hline MALAT1 & Metastasis associated lung adenocarcinoma transcript 1 (non-protein coding) & 4.371 & 0.022 \\
\hline CD69 & CD69 molecule & 3.906 & 0.006 \\
\hline CXCR4 & Chemokine (C-X-C motif) receptor 4 & 3.682 & 0.040 \\
\hline C12orf35 & Chromosome 12 open reading frame 35 & 3.637 & 0.045 \\
\hline CXCR4 & Chemokine (C-X-C motif) receptor 4 & 3.597 & 0.045 \\
\hline$M X D 1$ & MAX dimerization protein 1 & 3.585 & 0.008 \\
\hline PAPOLA & Poly(A) polymerase $\alpha$ & 3.558 & 0.030 \\
\hline KCNJ15 & Potassium inwardly-rectifying channel, subfamily J, member 15 & 3.515 & 0.041 \\
\hline$N A M P T$ & Nicotinamide phosphoribosyltransferase & 3.442 & 0.004 \\
\hline$H B P 1$ & HMG-box transcription factor 1 & 3.269 & 0.030 \\
\hline$M G A M$ & Maltase-glucoamylase ( $\alpha$-glucosidase) & 3.194 & 0.020 \\
\hline USP15 & Ubiquitin specific peptidase 15 & 3.151 & 0.028 \\
\hline PROK2 & Prokineticin 2 & 3.120 & 0.027 \\
\hline LOC 100289246 & Hypothetical protein LOC100289246 & 3.106 & 0.020 \\
\hline
\end{tabular}
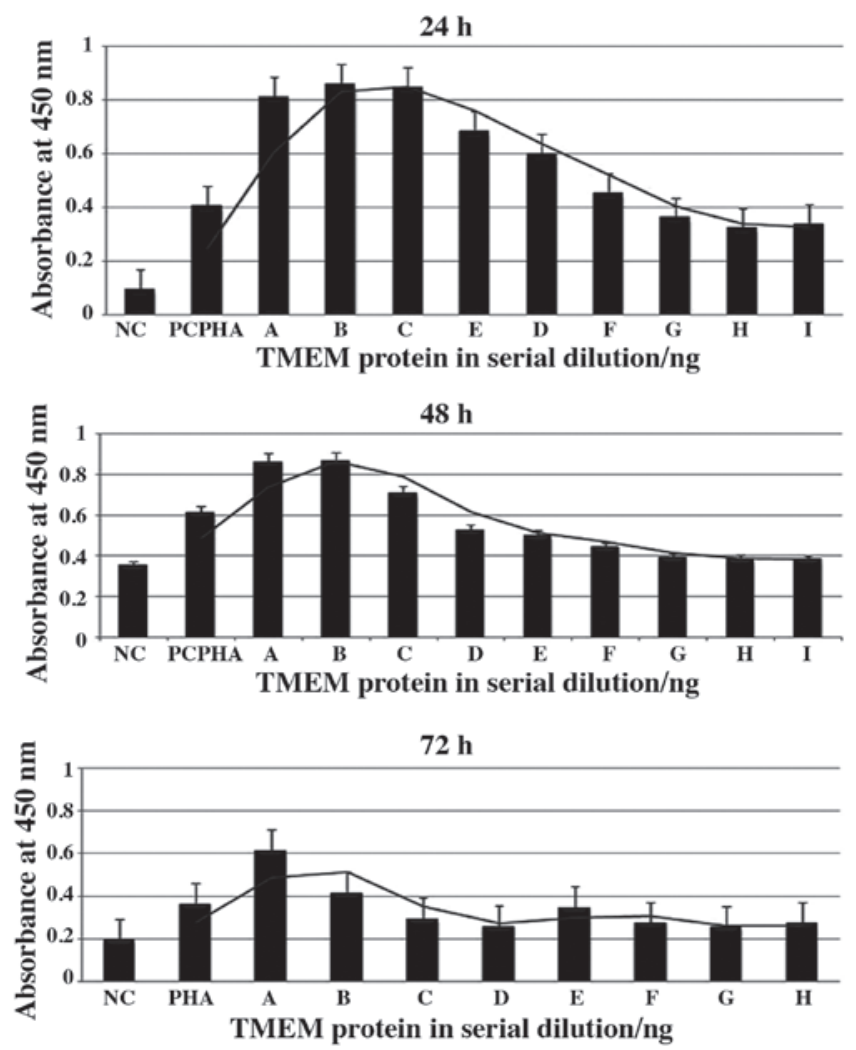

Figure 1. Effects of hypothetical transmembrane protein-66 (TMEM66) on human peripheral blood mononuclear cells (hPBMCs) proliferation. The effects after incubation for 24,48 and $72 \mathrm{~h}$ were measured by the WST Cell Proliferation assay. Negative (unstimulated cells) and positive controls (stimulated cells with $5 \mu \mathrm{g} / \mathrm{ml}$ PHA-M) were included. (A-H) Serial dilution of the TMEM66 protein (A, 340; B, 170; C, 85; D, 42.5; E, 21.25; F, 10.6; G, 5.3; H, 2.66; and I, 1.33 ng). Bars show the absorbance at $450 \mathrm{~nm}$ following treatment of the cells with the WST-1 reagent. Higher protein concentration had a significant proliferative effect compared to the negative control in all three periods $(\mathrm{P}<0.05)$. and experimental probes on the Affymetrix chips showed acceptable results. There were no outliers registered from the distribution of the intensities of the probes used.

Following the removal of deviated probe sets from the analysis, 493 out of $\sim 50,000$ transcripts were differentially expressed. Among these, 230 transcripts were upregulated while 263 were downregulated in the MS patients compared to the healthy subjects as $\mathrm{FC}$ was $1.5<\mathrm{FC}<-1.5$ with $\mathrm{P}<0.05$ (Tables I and II). The majority of the expressed genes are of known function in the databases and in certain literature, but one hypothetical protein with unknown function domain was found. This transcript, which is TMEM66, was differentially upregulated in the MS patients compared to the healthy individuals by 3 times ( $\mathrm{FC}, 3.106 ; \mathrm{P}=0.020$ ).

The expression of the upregulated genes was confirmed by $\mathrm{qPCR}$. The ratio concentration was derived from relative standard curves using the CP median values. The target to reference ratios of all the samples are referenced to the target to reference ratio of the calibrator. The results (target levels normalized to reference levels) showed that MS patients had a 3 -fold greater expression level of the TMEM66 gene compared to the control group.

Effects of TMEM66 protein on hPBMCs proliferation. To study the activity of TMEM66 on hPBMCs, the WST Cell Proliferation assay was used. The cells were incubated for 24, 48 and $72 \mathrm{~h}$ after stimulation with different concentrations of TMEM66 and PHA as the positive control. Certain cells were left untreated as negative controls. TMEM66 showed higher proliferative effects with all concentrations used in all three periods compared to unstimulated cells (negative control). The most significant proliferative effects were noted at $24 \mathrm{~h}$, followed by $48 \mathrm{~h}$ incubation $(\mathrm{P}<0.05)$ (Fig. 1). 
Table II. Downregulated transcripts of the multiple sclerosis patients compared to the healthy subjects.

\begin{tabular}{llrr}
\hline Gene symbol & \multicolumn{1}{c}{ Gene title } & Fold change & P-value \\
\hline DLEU2 & Deleted in lymphocytic leukemia 2 (non-protein coding) & -3.720 & 0.013 \\
APOBEC3B & Apolipoprotein B mRNA editing enzyme, catalytic polypeptide-like 3B & -3.648 & 0.032 \\
MCTP1 & Multiple C2 domains, transmembrane 1 & -2.803 & 0.040 \\
CLIC3 & Chloride intracellular channel 3 & -2.744 & 0.018 \\
SMAD1 & SMAD family member 1 & -2.534 & 0.043 \\
ZNF880 & Zinc finger protein 880 & -2.478 & 0.014 \\
TMEM106B & Transmembrane protein 106B & -2.421 & 0.049 \\
DLEU2 & Deleted in lymphocytic leukemia 2 (non-protein coding) & -2.420 & 0.027 \\
SRD5A3 & Steroid 5 a-reductase 3 & -2.419 & 0.033 \\
FAM43A & Family with sequence similarity 43, member A & -2.330 & 0.004 \\
RAPH1 & Ras association (RalGDS/AF-6) and pleckstrin homology domains 1 & -2.312 & 0.034 \\
C7orf36 & Chromosome 7 open reading frame 36 & -2.296 & 0.002 \\
NBPF1 & Neuroblastoma breakpoint family, member 1 & -2.295 & 0.013 \\
ZEB2 & Zinc finger E-box binding homeobox 2 & -2.243 & 0.016 \\
GPR18 & G protein-coupled receptor 18 & -2.231 & 0.004 \\
SOS1 & Son of sevenless homolog 1 (Drosophila) & -2.220 & 0.012 \\
ADRB2 & Adrenergic, $\beta$-2-, receptor, surface & -2.176 & 0.002 \\
C12orf73 & Chromosome 12 open reading frame 73 & -2.173 & 0.003 \\
QSER1 & Glutamine and serine rich 1 & -2.144 & 0.039 \\
CTAGE5 & CTAGE family, member 5 & -2.140 & 0.042 \\
PTGDS & Prostaglandin D2 synthase 21 kDa (brain) & -2.139 & 0.043 \\
TRIM32 & Tripartite motif-containing 32 & -2.128 & 0.001 \\
MRPS14 & Mitochondrial ribosomal protein S14 & -2.080 & 0.026 \\
ARL17A/B & ADP-ribosylation factor-like 17A /B & -2.067 & 0.036 \\
ZNF818P & Zinc finger protein 818 (pseudogene) & -2.032 & 0.047 \\
\hline
\end{tabular}

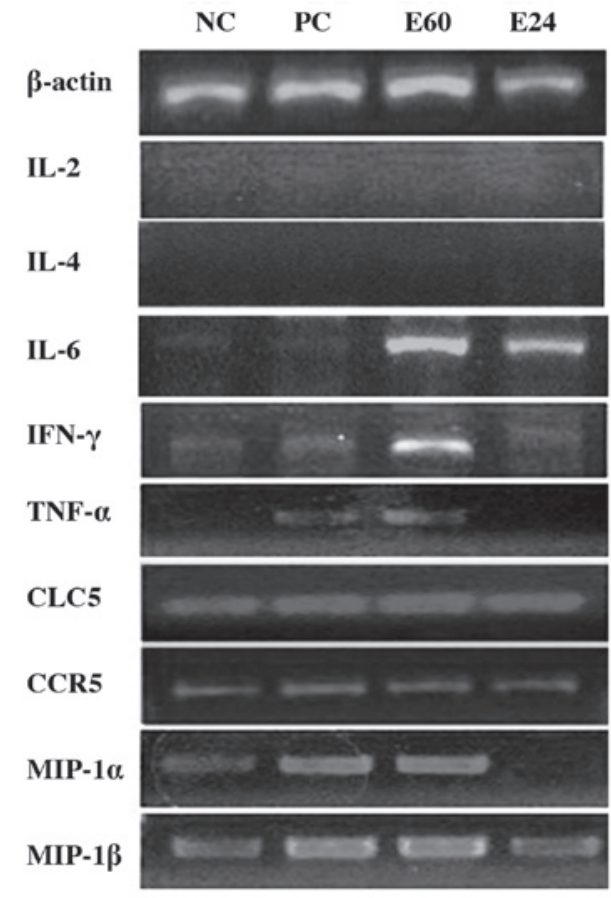

Figure 2. Activity of hypothetical transmembrane protein-66 (TMEM66) on cytokine and chemokine gene expression by reverse transcription-polymerase chain reaction. TMEM66 stimulation was compared to the reference gene $(\beta$-actin) at $60 \mathrm{~min}(\mathrm{E} 60)$ and $24 \mathrm{~h}(\mathrm{E} 24)$. NC, negative control; PC, positive control; IL, interleukin; IFN, interferon; TNF, tumor necrosis factor.
Activity of TMEM66 protein on cytokine and chemokine gene expression. The induction of potential proinflammatory cytokines and chemokines was examined by RT-PCR to demonstrate the expression of these mediators in response to TMEM66 stimulation and in comparison to the reference gene $(\beta$-actin) at 1 and $24 \mathrm{~h}$. The data showed induction of the proinflammatory cytokines IL-6, IFN- $\gamma$ and TNF- $\alpha$, and the chemokines CCL5, CCR5, MIP- $1 \alpha$ and MIP-1 $\beta$, but not the anti-inflammatory cytokine IL-4 or the growth factor cytokine IL-2. CCL5, CCR5 and MIP-1 $\beta$ were expressed at all the time points, but IL- 6 , IFN- $\gamma$, TNF- $\alpha$ and MIP-1 were mainly expressed after $1 \mathrm{~h}$ exposure to TMEM66 (Fig. 2).

\section{Discussion}

The recently reported increased prevalence of MS in the Middle East (6), the Gulf region $(7,8)$ and in Bahrain (Alsharoqi et al, 2014, unpublished data, where prevalence was found to be $50 / 100,1000)$ has stimulated the study of differential gene expression in Bahraini MS patients with an insight to detect novel genes that may correlate with the pathogenesis of MS. The data showed that a total of 493 genes were differentially expressed in MS patients and control individuals. A total of 230 genes were upregulated and 263 were downregulated with an FC range of -1.5 to +1.5 . Certain genes were of unknown function, such as TMEM66, which was found to be expressed 
3 times higher in Bahraini MS patients compared to the controls.

The TMEM66 protein is a hypothetical protein of unknown function. It contains 339 amino acids and belongs to the DUF1183 family. This family consists of several eukaryotic proteins of $\sim 360$ residues in length. Recently, Palty et al (27) identified the character of the TMEM66 gene product using a functional-based high-throughput screen [known as SOCE-associated regulatory factor (SARAF)] as a regulator of cellular $\mathrm{Ca}^{2+}$ homeostasis. SARAF is a highly conserved protein in vertebrates and has poor functional annotation. In mammals, SARAF is ubiquitously expressed, but has significantly high transcript levels in the immune and neuronal tissues (28). In other studies, the TMEM66 gene was expressed among different novel androgen-responsive genes in prostate cancer. Those genes were indicated to play a role in the molecular mechanisms of androgen-dependency of the prostate and were also considered as targets for therapy or biomarkers of prostate cancer $(29,30)$.

As TMEM66 was preferentially expressed in the present MS patients, the relevance to MS was explored by cloning the gene, producing the recombinant protein and testing it for immunological activity that is relevant to the pathogenesis of MS. The results depicted potential proinflammatory activity of the TMEM66 protein since it induced significant proliferation and increased induction of the proinflammatory cytokines IL-6, IFN- $\gamma$, TNF- $\alpha$ and the chemokines CCL5 and CCR5, MIP-1 $\alpha$ and MIP-1 $\beta$, but not the anti-inflammatory cytokine IL-4 or the growth factor cytokine IL-2. These data are supportive of the possible involvement of TMEM66 in the pathological events of MS in the patients, as MS is considered to be mainly mediated by immune response (31). The proinflammatory and anti-inflammatory responses were shown to have clear effects over the time in the progression of the disease (12).

Understanding the mediators of the inflammation profiles and their roles may help in the characterization of mechanisms involved in the pathogenesis of the disease and may help to monitor the disease course and evaluate the responses to specific therapies that may result in novel therapies directed at cytokines or their receptors. A multiplexed immunoassay was used to assess the concentrations of 13 cytokines/inflammatory markers, including IFN- $\gamma$; IL- $1 \beta,-2,-4,-5,-6,-8,-10$, -12 and -13; TNF- $\alpha$; IL-2 receptor; and soluble CD40 ligand. Significant increases in the patients compared to the control subjects for IFN- $\gamma$, IL-2, IL-1 $\beta$, TNF- $\alpha$, IL-4, IL-10 and IL-13 were noted (12).

In conclusion, determination of new genes that are relevant to pathogenetic development of MS in a particular population may help in addressing novel therapeutic approaches in molecular-targeted personalized medicine that is informed by the distinctive clinical, genetic, genomic makeup and environmental information for an individual. Thus, finding a unique gene that is preferentially expressed in a certain population and demonstrating a potential immune activity by the protein encoded by this gene is the first step to develop targeted diagnostics and therapeutic approaches to achieve more personalized management. TMEM66 may be a possible candidate in this regard. Further analysis are required to study the expression of this protein in MS patients from the Middle
East and Gulf region during different stages of the disease, and additionally, in order to identify a link between TMEM66 and the lesion pathogenesis of MS, it would be pertinent to study the expression of this molecule in the demyelinating lesion of MS prior to considering it as a relevant diagnostic, therapeutic and follow-up biomarker for the disease.

\section{Acknowledgements}

The present study received financial support from the College of Medicine and Medical Sciences, Arabian Gulf University, Bahrain.

\section{References}

1. Broux B, Stinissen P and Hellings N: Which immune cells matter? The immunopathogenesis of multiple sclerosis. Crit Rev Immunol 33: 283-306, 2013.

2. Küçükali CI, Kürtüncü M, Coban A, Cebi M and Tüzün E: Epigenetics of multiple sclerosis: an updated review. Neuromolecular Med: Mar 21, 2014 (Epub ahead of print).

3. Ascherio A: Environmental factors in multiple sclerosis. Expert Rev Neurother 13 (Suppl 12): 3-9, 2013.

4. Kenealy SJ, Pericak-Vance MA and Haines JL: The genetic epidemiology of multiple sclerosis. J Neuroimmunol 143: 7-12, 2003.

5. Noseworthy JH, Lucchinetti C, Rodriguez $M$ and Weinshenker BG: Multiple sclerosis. N Engl J Med 343: 938-952, 2000.

6. Alroughani RA and Al-Jumah MA: The need for a multiple sclerosis registry in the Gulf Region. Neurosciences (Riyadh) 19: 85-86, 2014.

7. Aljumah M, Alroughani R, Alsharoqi I, et al: Future of management of multiple sclerosis in the middle East: a consensus view from specialists in ten countries. Mult Scler Int 2013: 952321, 2013.

8. Bohlega S, Inshasi J, Al Tahan AR, Madani AB, Qahtani H and Rieckmann P: Multiple sclerosis in the Arabian Gulf countries: a consensus statement. J Neurol 260: 2959-2963, 2013.

9. Al-Afasy HH, Al-Obaidan MA, Al-Ansari YA, et al: Risk factors for multiple sclerosis in Kuwait: a population-based case-control study. Neuroepidemiology 40: 30-35, 2013.

10. Prat E and Martin R: The immunopathogenesis of multiple sclerosis. J Rehabil Res Dev 39: 187-199, 2002.

11. Achiron A, Gurevich M, Magalashvili D, Kishner I, Dolev M and Mandel M: Understanding autoimmune mechanisms in multiple sclerosis using gene expression microarrays: treatment effect and cytokine-related pathways. Clin Dev Immunol 11: 299-305, 2004.

12. Martins TB, Rose JW, Jaskowski TD, et al: Analysis of proinflammatory and anti-inflammatory cytokine serum concentrations in patients with multiple sclerosis by using a multiplexed immunoassay. Am J Clin Pathol 136: 696-704, 2011.

13. Kolbert CP, Taylor WR, Krajnik KL and O'Kane DJ: Gene expression microarrays. Methods Mol Med 85: 239-255, 2003.

14. Watson A, Mazumder A, Stewart M and Balasubramanian S: Technology for microarray analysis of gene expression. Curr Opin Biotechnol 9: 609-614, 1998.

15. Baranzini SE and Hauser SL: Large-scale gene-expression studies and the challenge of multiple sclerosis. Genome Biol 3: 1027,2002

16. Polman CH, Reingold SC, Banwell B, et al: Diagnostic criteria for multiple sclerosis: 2010 revisions to the McDonald criteria. Ann Neurol 69: 292-302, 2011.

17. Zanzinger K, Schellack C, Nausch N and Cerwenka A: Regulation of triggering receptor expressed on myeloid cells 1 expression on mouse inflammatory monocytes. Immunology 128: 185-195, 2009.

18. Rasmussen R: Quantification on the LightCycler. In: Rapid Cycle Real-Time PCR, Methods and Applications. Meuer S, Wittwer C and Nakagawara K (eds). Springer Press, Heidelberg, pp22-34, 2001.

19. Ausubel FM, Brent R, Kingston RE, Moore DD, Seidman JG, Smith JA and Struhl K (eds): Current Protocols in Molecular Biology. John Wiley \& Sons, New York, NY, 1994. 
20. Decker T and Lohmann-Matthes ML: A quick and simple method for the quantitation of lactate dehydrogenase release in measurements of cellular cytotoxicity and tumor necrosis factor (TNF) activity. J Immunol Methods 115: 61-69, 1988

21. Korzeniewski $C$ and Callewaert DM: An enzyme-release assay for natural cytotoxicity. J Immunol Methods 64: 313-320, 1983.

22. Chomczynski P: A reagent for the single-step simultaneous isolation of RNA, DNA and proteins from cell and tissue samples. Biotechniques 15: 532-534, 536-537, 1993.

23. Chomczynski P and Sacchi N: Single-step method of RNA isolation by acid guanidinium thiocyanate-phenol-chloroform extraction. Anal Biochem 162: 156-159, 1987.

24. Hummon AB, Lim SR, Difilippantonio MJ and Ried T: Isolation and solubilization of proteins after TRIzol extraction of RNA and DNA from patient material following prolonged storage. Biotechniques 42: 467-470, 472, 2007.

25. Irizarry RA, Hobbs B, Collin F, et al: Exploration, normalization and summaries of high density oligonucleotide array probe level data. Biostatistics 4: 249-264, 2003.
26. Wu Z, Irizarry R, Gentlemen R, et al: A model-based background adjustment for oligonucleotide expression arrays. J Am Statist Assoc 99: 909-917, 2004

27. Palty R, Raveh A, Kaminsky I, Meller R and Reuveny E: SARAF inactivates the store operated calcium entry machinery to prevent excess calcium refilling. Cell 149: 425-438, 2012

28. Su AI, Wiltshire T, Batalov S, et al: A gene atlas of the mouse and human protein-encoding transcriptomes. Proc Natl Acad Sci USA 101: 6062-6067, 2004.

29. Romanuik TL, Wang G, Holt RA, Jones SJ, Marra MA and Sadar MD: Identification of novel androgen-responsive genes by sequencing of LongSAGE libraries. BMC Genomics 10: 476, 2009.

30. Romanuik TL, Ueda T, Le N, et al: Novel biomarkers for prostate cancer including noncoding transcripts. Am J Pathol 175: 2264-2276, 2009.

31. Hartung HP, Aktas O, Menge T and Kieseier BC: Immune regulation of multiple sclerosis. Handb Clin Neurol 122: 3-14, 2014. 